\title{
Sequence effects support the conflict theory of N2 and P3 in the Go/NoGo task
}

Janette L. Smith, Elizabeth A. Smith, Alexander L. Provost and Andrew Heathcote

School of Psychology, University of Newcastle, Australia

Running head: Sequence effects on N2 and P3 in the Go/NoGo task

Number of pages: 29

Number of Tables: 0

Number of Figures: 4

Corresponding author:

Janette L Smith

School of Psychology,

University of Newcastle

Ourimbah NSW 2258

Australia

Telephone: +61243484149

Fax: +612 43484145

Email: janette.smith@newcastle.edu.au 


\begin{abstract}
In two-choice tasks the preceding sequence of stimuli robustly influences both the P3 ERP component and reaction time (RT) to the current stimulus. We examined sequence effects in both two-choice and Go/NoGo tasks to distinguish between inhibition and conflict accounts of the N2 and P3 components. RT results suggested similar subjective expectancies were generated in the Go/NoGo and two-choice task. N2 was increased for all unexpected stimuli, even when no response inhibition was required, consistent with a conflict interpretation. The Go/NoGo P3 results also suggested a conflict explanation, and that this conflict was reduced if the response had been recently performed. These results support a reconsideration of the roles of N2 and P3 in all inhibition and conflict tasks, and the Go/NoGo task in particular.
\end{abstract}

Descriptors: N2; P3; Go/NoGo; sequence effects; response competition; conflict 


\section{Introduction}

In the Go/NoGo task, participants must respond to Go stimuli and not respond to NoGo stimuli. For NoGo compared to Go trials, the N2 component of the event-related potential (ERP) is robustly increased at frontal sites, and the P3 is increased at frontocentral sites (e.g., Bekker, Kenemans, \& Verbaten, 2004; Bruin \& Wijers, 2002; Jodo \& Kayama, 1992, Smith, Johnstone \& Barry, 2006, 2008). One interpretation of these increases is that they reflect some aspect of inhibitory processing (e.g., Gemba \& Sasaki, 1989; Kok, 1986). However, this interpretation is clouded by different N2 and P3 effects in other tasks requiring inhibition. For example, when participants fail to inhibit a response in a stop-signal task the N2 is increased, but the $\mathrm{P} 3$ decreased, compared to trials where response inhibition is successful (Bekker, Kenemans, Koeksma, Talsma, \& Verbaten, 2005; Dimoska, Johnstone, \& Barry, 2006; Kok, Ramautar, De Ruiter, Band, \& Ridderinkhof, 2004). These results may indicate that only the P3 is associated with inhibition, while the N2 may overlap with error-related components. Conversely, only the N2 appears associated with inhibition in the Eriksen flanker task, as the N2 is increased to targets with incompatible compared to compatible flankers, whereas the P3 is unaffected by flanker compatibility (e.g., Gehring, Gratton, Coles, \& Donchin, 1992; Heil, Osman, Wiegelmann, Rolke, \& Hennighausen, 2000; Kopp, Mattler, Goertz, \& Rist, 1996; van Veen \& Carter, 2002).

Interpretation of the N2 and P3 purely in terms of response inhibition is also inconsistent with the fact that $\mathrm{N} 2$ and $\mathrm{P} 3$ differences are observed in tasks that require no inhibition in the sense of stopping an overt response. These effects are found in tasks that produce conflict between competing decisions or responses even though participants make a response on every trial, such as when a planned response must be changed, or when a low-frequency response must be made instead of a high-frequency response. For example, in Posner-style tasks, the N2 is sometimes larger to invalidly cued targets (Band, Ridderinkhof, \& van der Molen, 2003; but see Smith, Johnstone, \& Barry, 2007 for the opposite effect), while the P3 is robustly increased (Band et al., 2003; Gehring et al., 1992; Ofek \& Pratt, 2004; Smith et al., 2007). Other researchers have shown that the N2 and P3 are increased when unexpected responses had to be activated: Donkers and van Boxtel (2004) showed that the N2 and P3 increased in situations where participants must unexpectedly increase response activation to produce a response with higher force than normal, while Nieuwenhuis, Yeung, van den Wildenberg and Ridderinkhof (2003) varied Go stimulus 
probability and showed that the N2 was increased for rare relative to frequent trials, whether Go or NoGo. Thus, increased N2 and P3 components are also observed when conflict between competing responses occurs due to participants changing their planned response to a different one in Posner-type tasks, increasing the strength of response, or making a rare response in the context of a frequent one. Thus, some researchers have argued that the Go/NoGo task is a special case of other conflict-inducing tasks requiring a choice between two decisions/responses (e.g., Band et al., 2003; Donkers \& van Boxtel, 2004; Gomez, Ratcliff \& Perea, 2007).

The studies just reviewed indicate effects due to expectancy about an upcoming target stimulus. Presumably, the greater the expectancy, the more a response can be planned, and hence the greater the inhibition and/or conflict produced when an unexpected stimulus occurs. Stimulus expectancy can be experimentally manipulated either explicitly, via instructions that a particular cue predicts a particular target, or implicitly, by varying stimulus probabilities. However, expectancies do not always have to be experimentally manipulated as participants spontaneously generate expectancies for the current stimulus based on the previous sequence of stimuli, even when the sequence is random. Such effects have been most often studied in speeded two-choice tasks, where participants respond to stimuli of one type $(\mathrm{X})$ with the left hand, and to stimuli of another type $(\mathrm{Y})$ with the right hand. First-order sequence effects relate to the transition from trial $n-1$ to trial $n$, which is classified as a repetition (R) of stimulus and response (e.g., $\mathrm{XX}$ ) or an alternation (A, e.g., YX, where $\mathrm{X}$ is the most recent stimulus). In this paper we focus solely on the results observed with long $(>500 \mathrm{~ms})$ response-to-stimulus intervals (RSIs); we note that with shorter RSIs, different effects, with different purported explanations, are observed. With compatible mapping of stimuli to responses, and with a long RSI, responses are usually faster to first-order alternations than repetitions (e.g., Bertelson, 1961; Kirby, 1976).

Higher-order effects occur when stimuli further back in the sequence affect the response to the current stimulus. When RSIs are long, RT decreases over runs of repetitive stimuli (e.g., $\mathrm{XXXX}=\mathrm{RRR}$ ) and over runs of alternating stimuli (e.g., YXYX=AAA). In contrast, RT is longer, and errors more likely, if a run is discontinued (e.g., XXXY=RRA or XYXX=AAR) (Jentzsch \& Sommer, 2002; Laming, 1968; Remington, 1969, 1971). In general, performance improves over the sequences $\mathrm{RRx}, \mathrm{ARx}, \mathrm{RAx}, \mathrm{AAx}$ in a first-order alternation condition (i.e., when $\mathrm{x}=\mathrm{A}$ ), and deteriorates over this sequence in a first-order repetition condition (i.e., when $\mathrm{x}=\mathrm{R}$ ). These data conform to a "cost-benefit" pattern (Soetens, 1998), such that a benefit is associated with stimuli that continue a run (of repetitions or alternations) and a cost is associated 
with stimuli that discontinue a run. Statistically, a cost-benefit pattern is indicated by an interaction between first-order and higher-order sequence factors, usually in the absence of a higher-order main effect. Soetens has argued that these sequence effects with long RSIs are due to participants' subjective expectancies. In general, participants expect more alternation and less repetition than actually occurs in a truly random sequence (the Gambler's fallacy; Jarvik, 1951), producing better performance for first order alternations than repetitions. Participants also expect the continuation of any runs, whether of alternations or repetitions, producing the observed higher-order sequence effects. The subjective expectancy process is thought to always be active, but to require a minimum time to influence behaviour, and hence it is usually seen only with long RSIs (Sommer, Leuthold \& Soetens, 1999). Soetens locates the influence of expectancy at later (response-related) processing stages.

ERP research has shown that, in easy two-choice tasks with a long RSI, P3 amplitude mirrors the cost-benefit pattern: P3 decreases for stimuli that continue a run (of repetitions or alternations), and increases for stimuli that discontinue a run (Jentzsch \& Sommer, 2001; Matt, Leuthold, \& Sommer, 1992; Sommer et al., 1999; Sommer, Matt, \& Leuthold, 1990). Effects for P3 latency have not been studied extensively, and preliminary results appear equivocal: although Sommer et al. (1990) noted no first order effects, Matt et al. (1992) found a shorter P3 latency for alternations than repetitions. Although both of these authors agree that P3 latency shows a higher-order cost-benefit pattern, with decreases over runs of repetitive or alternating stimuli, and increased P3 latency to the stimulus that discontinues the run, other researchers have contradicted this last result, showing decreased P3 latency to the target that ends a long versus short run of repetitive stimuli (Golob \& Starr, 2000; Starr, Sandroni \& Michalewski, 1995; Gonsalvez \& Polich, 2002). Amplitude effects are more consistent, and form part of the rationale for the influential 'context updating' model of P3 (Donchin \& Coles, 1988). In terms of Soetens' (1998) subjective expectancy model, it appears that when expectancies are met responses are faster, errors are unlikely and the P3 is smaller, but when expectancies are not met responses are slower, errors more likely and $\mathrm{P} 3$ is larger.

Our experiment examines random sequence effects in the Go/NoGo task. If subjective expectancy affects behaviour and ERPs for a stimulus requiring a response in the two-choice task, then it may also determine behaviour and the ERP to stimuli which do not require a response in the Go/NoGo task. Trials which discontinue a run are relatively unexpected, and therefore might elicit greater response inhibition and/or response conflict. Recent behavioural 
research has shown that first- and second-order trial sequences are important for theories of conflict in the flanker task (Nieuwenhuis, Stins, Posthuma, Polderman, Boomsma \& De Geus, 2006) and for explanations of post-error slowing in the stop-signal task (Verbruggen, Logan, Liefooghe \& Vandierendonck, 2008). We know of only one other study, Nieuwenhuis et al. (2003), which has examined sequence effects on ERPs in the Go/NoGo task. They found a slower Go response for first-order alternations (i.e., the previous stimulus required a NoGo response) than first-order repetitions (i.e., the previous stimulus required a Go response). Errors on NoGo trials (i.e., commission errors) were also less frequent if the previous stimulus required a NoGo response (i.e., a first-order repetition) than if it required a Go response (i.e., a first order alternation). In addition, the increase in N2 for NoGo relative to Go stimuli was smaller for trials following a NoGo than a Go stimulus, which they attributed to transient priming of the NoGo stimulus. No analyses of P3 or higher-order sequence effects were reported. In the current study we collected enough trials to analyse higher-order effects, and we report analyses of both $\mathrm{N} 2$ and $\mathrm{P} 3$ components.

Although only one study has looked at random sequence effects in the Go/NoGo task, two other studies have produced related findings. One set comes from two of the most influential studies on the P3 component (Squires, Petuchowski, Wickens, \& Donchin, 1977; Squires, Wickens, Squires, \& Donchin, 1976). These studies can be seen as using a Go/NoGo task with covert responses, as participants were presented with equiprobable stimuli and asked to count those of one type, and ignore the other. Analyses focused on an enhanced P3 to trials which discontinued a repetitive run, and this effect was apparent for runs of both count (covert Go) and no-count (covert NoGo) trials. Consistent results were reported for the N2 as well as the P3 using a similar methodology by Sams, Alho and Näätänen (1983). Results reported in Squires and colleagues' $(1976,1977)$ figures indicate that P3 was larger for count and no-count trials that discontinued an alternating run, but they did not report detailed analyses. Furthermore, the use of a covert counting response does not allow any analysis of sequence effects on behaviour, such as RT and errors.

A second set of related findings comes from Durston and colleagues (Durston, Thomas, Worden, Yang, \& Casey, 2002; Durston, Thomas, Yang, Ulug, Zimmerman, \& Casey, 2002). They presented 1,3 or 5 Go trials before each NoGo trial, and found that commission errors for NoGo stimuli were increased following long compared to short runs of Go stimuli. Furthermore, activation of the cingulate gyrus, an area strongly associated with inhibitory control 
(e.g., Garavan, Ross, Murphy, Roche, \& Stein, 2002), was increased for NoGo trials following long compared to short runs of Go trials. This is promising evidence that inhibitory/conflict processing differs based on higher-order stimulus sequences. However, there are problems associated with the use of non-random sequences. For example, results for the longest Go sequence may be affected if participants learn that a sequence of five Go trials is always followed by a NoGo stimulus. Additionally, because the NoGo stimulus never repeated, and so sequences of alternating stimuli were not possible, neither the effects of NoGo repetition, nor the effects of expectancy about alternation, could be examined.

These methodological limitations on the study of sequence effects extend to designs using frequent-Go and rare-NoGo trials. Such designs are used because of debate about whether equiprobable Go/NoGo tasks reliably induce inhibition (e.g., Braver, Barch, Gray, Molfese \& Snyder, 2001). However, the same ERP differences are usually found in equiprobable and rare Go tasks (Bokura et al., 2001; Mäntysalo, 1987; Pfefferbaum \& Ford, 1988; van Boxtel, van der Molen, Jennings \& Brunia, 2001; Bruin \& Wijers, 2002; Nativ, Lazarus, Nativ \& Joseph, 1992; Nieuwenhuis et al., 2003, but see Wang, Tian, Wang, Cui \& Zhang, 2002, for no difference on the N2), and it appears that the same areas of brain are activated (Vallesi, McIntosh, Alexander \& Stuss, 2009; Mostofsky et al., 2003; Garavan, Hester, Murphy, Fassbender \& Kelly, 2006; Rubia et al., 2001; Watanabe et al., 2002). These results indicate that equiprobable Go/NoGo tasks usually do elicit the same type of neural processing as frequent-Go/rare-NoGo tasks.

In the current study, it was necessary to use an equiprobable design, since the subjective expectancy theory arises from situations where not only each trial type is equiprobable, but also where each higher-order sequence is equiprobable. With globally different trial probabilities it is difficult to make strong predictions about, or accurately measure the effects of, expectancy. If Go stimuli are frequent, long runs of repetitive Go stimuli become very probable, and runs of alternating Go and NoGo stimuli become improbable, as do long runs of repetitive NoGo stimuli. Furthermore, it is unclear what processes are elicited by trials which discontinue a long run of repetitive stimuli (e.g., GGGN sequence) when global probabilities are unequal. An alternation might be unexpected, because participants generally expect runs of repetitions to continue. Conversely, the alternation might be highly expected, since participants must have some (probably implicit) knowledge of the global trial probabilities. Given these difficulties, in the current study, we use a random and equiprobable presentation of Go and NoGo trials. 
In summary, the present study reports the first in-depth examination of higher-order sequence effects in an equiprobable and random Go/NoGo task, in conjunction with a two-choice RT task. It represents an improvement on previous studies of sequence effects in the Go/NoGo task by requiring overt button press responses (Squires et al., 1976; 1977), using an equiprobable task (Durston, Thomas, Worden et al., 2002; Durston, Thomas, Yang et al., 2002), and by considering the effects of higher-order as well as first-order sequences (Nieuwenhuis et al., 2003). The principal aim of the study is to distinguish the inhibitory and conflict interpretations of $\mathrm{N} 2$ and P3. If a component reflects response inhibition in the Go/NoGo task, it should be generally larger for NoGo compared to Go trials, as well as being increased for unexpected relative to expected NoGo trials. That is, we expect a cost-benefit pattern similar to that observed in two-choice tasks for NoGo but not for Go trials, since inhibition of an overt response is not required on these trials. However, if a component reflects conflict, it should not be generally larger for NoGo than Go trials, since both types could produce conflict when they are unexpected. Furthermore, a cost-benefit pattern should be displayed for both Go and NoGo stimuli. That is, we should observe increases in the component to any unexpected stimulus (i.e., a stimulus that discontinues a run), whether Go or NoGo.

\section{Method}

\section{Participants}

Participants were 23 adults (17 female) with a mean age of 22.5 years (SD 8.1 years) who participated to fulfil an undergraduate course requirement. Four participants were left-handed. Participants had not consumed caffeine in the two hours prior to testing, and reported no illicit drug use in the $24 \mathrm{~h}$ prior to testing, nor more than once a month for the past 6 months. In addition, none had any evidence of seizure-related disorders, vision or hearing problems, or were taking any medication. The research protocol was approved by the Human Research Ethics Committee of the University of Newcastle before data collection began.

\section{Apparatus and stimuli}

All participants completed 4 blocks each of a Go/NoGo and two-choice task. Stimuli were filled circles (2.1 deg of visual angle) presented above a central fixation cross for $200 \mathrm{~ms}$. A mean stimulus onset asynchrony (SOA) of $1.2 \mathrm{~s}$ was used (range 1.0 to 1.4s): two-choice tasks usually use a fixed RSI, but this method is not suitable for the Go/NoGo task in which responses are withheld on $50 \%$ of trials. Thus, the two-choice task is included here to confirm that the use of a 
random ISI, rather than fixed RSI, does not alter the cost-benefit patterns in RT. In the twochoice task, blue circles required a button press response with the right index finger, and yellow circles required a button press response with the left index finger. In the Go/NoGo task, green circles required a button press response with the index finger and red circles required no response. Participants switched the responding hand for Go trials between blocks, and the hand with which they began was counterbalanced between participants. Trials were presented in a random, equiprobable fashion, with 960 trials for each task. Eleven participants performed the Go/NoGo task first. Participants completed a practice block of 20 trials before the experimental blocks began for each task.

\section{Procedure}

Participants were familiarised with the testing procedure and laboratory before providing informed consent and completing a demographic questionnaire. Once electrodes were fitted, participants were seated in the testing room. Instructions for the task appeared on a computer screen for the participant to read, and understanding was checked verbally. Participants were encouraged to keep as still as possible throughout the task, and speed and accuracy were equally stressed.

\section{Electrophysiological recording}

An electrode cap containing tin electrodes was fitted, with continuous EEG recorded from 26 scalp sites (Fp1, Fpz, Fp2, F7, F3, Fz, F4, F8, FC3, FCz, FC4, T7, C3, Cz, C4, T8, CP3, CPz, CP4, P7, P3, Pz, P4, P8, O1 and O2) of the International 10-20 system. Cap electrodes were referenced to an electrode on the tip of the nose. Vertical EOG was measured with tin cup electrodes placed $1 \mathrm{~cm}$ above and below the left eye, and horizontal EOG was measured from electrodes placed $1 \mathrm{~cm}$ lateral to the outer canthi. Additional tin cup electrodes were placed on the left and right mastoids. Electrode impedances were below $5 \mathrm{k} \Omega$. The participant was grounded by a cap electrode located midway between Fpz and Fz. Signals were amplified 1000 times with a bandpass between 0.1 and $40 \mathrm{~Hz}$, and sampled at $500 \mathrm{~Hz}$.

\section{Data analysis}

Trials were sorted post-experimentally by the current stimulus type as well as the sequence of the preceding three stimuli, producing eight sequence conditions. The first four trials in each block were excluded from further analysis as their sequence classification was undefined. Trials were scored as an error when there was a response on a NoGo trial (commission error), no response 
on a Go trial (omission error) or when no response or the wrong response was made on a twochoice trial. Any trial on which more than one response was made was also scored as an error. To avoid problems attending the non-normal distributions of error rates, they were calculated as the number of trials on which any type of error occurred plus 0.5 divided by the total number of trials plus 1 (Snodgrass \& Corwin, 1988), and subject to an inverse cumulative normal (Z) transform before analysis. Results for individual participants were averaged on the $\mathrm{Z}$ scale and standard errors were calculated on the $\mathrm{Z}$ scale, then averages and standard error intervals transformed back to the error rate scale for display. Mean RT for each participant was calculated using trials that a) were not scored as an error and did not occur after a trial that was scored as an error and b) had a RT greater than $100 \mathrm{~ms}$. The latter condition was imposed to avoid anticipations and late responses from the previous trial. Such responses were observed, on average, for $0.32 \%$ of two-choice trials and $0.12 \%$ of Go trials. On average, the last trial was an error for $12.6 \%$ of two-choice trials and $3.7 \%$ of Go/NoGo trials. In combination, these exclusions resulted, on average, in mean correct RT being based on 77\% of two-choice trials and $92.7 \%$ of $\mathrm{Go} / \mathrm{NoGo}$ trials.

The EEG was re-referenced to linked mastoids and corrected for eye movements using Neuroscan's in-built procedure (Semlitsch, Anderer, Schuster, \& Presslich, 1986). The continuous EEG was filtered with a bandpass from $0.5 \mathrm{~Hz}$ (down $12 \mathrm{~dB} / \mathrm{oct}$ ) to $15 \mathrm{~Hz}$ (down $12 \mathrm{~dB} /$ oct, zero phase shift). The ERP epoch began $100 \mathrm{~ms}$ before and ended $900 \mathrm{~ms}$ after stimulus presentation. Epochs were baselined to pre-stimulus activity, and trials with amplitudes exceeding $\pm 100 \mu \mathrm{V}$ in any scalp channel were rejected, as were error and post-error trials. The mean number of trials accepted for each average ranged between 48 and 96 over conditions. Peaks were detected within a specified latency range at a specified site (220-320 ms at Fz for N2, 310-410 $\mathrm{ms}$ at $\mathrm{Fz}$ for frontal (NoGo) P3a, and 280-380 ms at Pz for parietal P3b), and then amplitude measurements were taken at the same latency for all other sites for creation of topographic maps (Picton, et al., 2000).

\section{Statistical analysis}

Mean RT for correct responses was subjected to a repeated measures ANOVA with the factors Task Type (Go/Two-choice) x First-order sequence (Repetition: R vs. Alternation: A) x Higher-order sequence. The Higher-order sequence factor had levels in the order: RRx, ARx, RAx, AAx, where the most recent transition is listed last, and $\mathrm{x}$ is a placeholder for the first-order transition. Polynomial contrasts were applied to the higher-order factor as, for the long RSIs used here, 
error rates and mean RT in two-choice tasks have been found to be an approximately linear function of this order (e.g., Jentzsch \& Sommer, 2002). In particular, in the first-order sequence repetition condition error rates and mean RT have been found to increase linearly from RRR to AAR, whereas in the first-order alternation condition they decreased linearly from RRA to AAA. Hence, the cost-benefit pattern causes a strong interaction between first- and higher-order factors, and the linear contrast should explain most of the variance accounted for by the higherorder factor. We report the percentage of variance accounted for by the linear contrast as calculated by dividing the sum of squares for the linear contrast by the total sum of squares for the effect. Normalised error data were subjected to an analogous repeated measures ANOVA except that the Task Type factor was replaced with a Response Type (Go/NoGo/Two-choice) factor. Planned contrasts on the Response Type factor separately compared Go with NoGo and Go with Two-choice trials; the former comparison examines processes related to response execution and inhibition, while the latter compares response execution between the two tasks.

For the N2, frontal P3a and parietal P3b components, analyses of peak amplitude were restricted to the sites $\mathrm{Fz}$ (N2 and frontal P3a) and $\mathrm{Pz}$ (parietal P3b), although information at other scalp sites is represented in topographic maps. N2, P3a and P3b amplitude and latency measures were subjected to a repeated measures ANOVA with the factors Response Type $\mathrm{x}$ First-order sequence $\mathrm{x}$ Higher-order sequence. As we used planned single degree of freedom contrasts, and there were no more contrasts than the degrees of freedom for any effect (in both behavioural and ERP analyses), no Bonferroni-type adjustments to alpha were necessary (Tabachnick \& Fidell, 1996). All tests have $(1,22)$ degrees of freedom unless reported otherwise. Such single degree of freedom contrasts preclude the problems of nonsphericity often encountered with repeatedmeasures analyses, thus avoiding the need for their control using Greenhouse-Geisser type epsilon adjustments (O’Brien \& Kaiser, 1985).

\section{Results}

\section{Behavioural performance}

Figure 1 (top) displays the mean RT over trial sequences for correct responses to Go and twochoice stimuli. Performance is plotted as a function of trial sequence, with first-order repetition results presented on the left and first-order alternation results on the right. The cost-benefit pattern is evident as an increasing line on the left for the first-order repetition condition and a decreasing line on the right for the first-order alternation condition. Importantly, the cost-benefit 
pattern was obtained not only in the two-choice data but also in the Go condition, as evidenced by a highly significant first-order $\mathrm{x}$ higher-order (linear) interaction $(\mathrm{F}=154.1, \mathrm{p}<.001$, partial $\left.\eta^{2}=.875\right)$ and a negligible interaction of this effect with Go vs. two-choice responses $(F<1$, partial $\left.\eta^{2}=.009\right)$. The linear contrast on higher-order sequence explained $95.8 \%$ of variance in the interaction between first-order and higher-order factors. RT increased over higher-order sequences (a cost-only effect), with a linear trend accounting for $74.0 \%$ of the variance of the higher-order factor (calculated as the sum of squares for the linear contrast as a percentage of the sum of squares for the main effect; $\mathrm{F}=17.0, \mathrm{p}<.001$, partial $\eta^{2}=.436$ ). This is equivalent to saying that the magnitude of the positive slope of the higher-order sequence effect for first-order repetitions was greater than the magnitude of the negative slope for first-order alternations. There was also a significant first-order main effect, such that repetitions were faster than alternations $\left(\mathrm{F}=23.7, \mathrm{p}<.001\right.$, partial $\left.\eta^{2}=.518\right)$ and responses were significantly faster to Go than two-choice stimuli $\left(F=33.1, \mathrm{p}<.001\right.$, partial $\left.\eta^{2}=.601\right)$, but these effects did not interact $\left(\mathrm{F}<1\right.$, partial $\left.\eta^{2}=.001\right)$.

\section{$<<$ Insert Figure 1 about here $>>$}

Figure 1 (bottom) shows the error rates for two-choice, Go and NoGo trials. Note that, to aid interpretation, group means and standard errors on the $\mathrm{Z}$ scale were inverse-transformed back to percentages before plotting. Sequence effects on error rates were strikingly different for the three response types, as reflected in the highly significant three-way interaction (omnibus ANOVA F $(6,132)=13.9, \mathrm{p}<.001$, partial $\left.\eta^{2}=.388\right)$. To explore this effect we performed separate twoway (first-order x higher-order) ANOVAs for each response type.

Errors for the two-choice responses showed the same cost-benefit pattern as mean RT: the firstorder $\mathrm{x}$ linear higher-order interaction was strongly significant $\left(\mathrm{F}=70.9, \mathrm{p}<.001\right.$, partial $\eta^{2}$ $=.763$ ) with the linear contrast on the higher-order factor accounting for $99.4 \%$ of variance in the overall interaction. A first-order main effect was apparent $\left(\mathrm{F}=4.6, \mathrm{p}=.042\right.$, partial $\eta^{2}=$ .174), such that slightly more errors were made for first-order alternations than repetitions. The linear trend accounted for $84.0 \%$ of the variance in the higher-order factor $(F=20.6, p<.001$, partial $\eta^{2}=.483$ ), such that errors increased from runs of repetitions to runs of alternations, regardless of the first-order transition. 
Omission errors to Go stimuli were rare overall $(\sim 3 \%)$ and did not show a cost-benefit pattern because there was almost no effect of trial sequence; neither the first-order effect, nor higherorder linear contrast, nor the interaction with first-order sequence reached significance (first order main effect: $\mathrm{F}=3.6, \mathrm{p}=.070$, partial $\eta^{2}=.141$; higher-order main effect: $\mathrm{F}<1$, partial $\eta^{2}$ $=.020$; interaction $\mathrm{F}=1.2, \mathrm{p}=.276$, partial $\left.\eta^{2}=.054\right)$. NoGo (commission) errors in the firstorder alternation condition showed a strong cost-benefit pattern, whereas there was almost no effect of higher-order sequence on commission errors in the first-order repetition condition, as evidenced by a significant first-order $x$ linear higher-order interaction effect $(F=43.2, p<.001$, partial $\left.\eta^{2}=.677\right)$. A first-order main effect also reached significance, such that errors were more likely for first-order alternations $\left(F=19.6, \mathrm{p}<.001\right.$, partial $\left.\eta^{2}=.471\right)$, and the higher-order main effect was also significant, with errors decreasing from runs of repetitions to runs of alternations $\left(\mathrm{F}=5.7, \mathrm{p}=.026\right.$, partial $\left.\eta^{2}=.207\right)$.

\section{Event-related potentials}

The grand mean ERPs for all conditions are plotted in Figure 2. The N2 component appears frontally maximal and peaks around $260 \mathrm{~ms}$. It appears to show consistent effects of trial sequence for all stimulus types, with increasing amplitude over higher-order sequences for firstorder repetitions, and decreasing amplitude over higher-order sequences for first-order alternations, consistent with a cost-benefit pattern. Our decision to analyse separate P3a and P3b components appears justified by the differential pattern at frontal and parietal sites: All stimulus types show some evidence of a cost-benefit effect at $\mathrm{P} z$, while these effects appear missing for Go trials at Fz.

$<<$ Insert Figure 2 about here $>>$

Results for the first and last levels of the higher-order sequence factor are replotted in Figure 3 to make direct comparison of sequence effects among response types easier. In this figure, the greater $\mathrm{N} 2$ for NoGo than Go trials is apparent at Fz for first-order repetition sequences, but this effect reverses for first-order alternations. A frontal increase for NoGo relative to Go P3, as has also been reported previously, was only observed for the most difficult first-order alternation (RRA) sequence, with a smaller effect for the AAA sequence, and a reversal of the effect for first-order repetition sequences. Statistical analysis of N2, P3a and P3b peak amplitude and latency, reported next, confirm these observations. 
N2 peak amplitude (see Figure 4 for plots of peak amplitude at midline sites) showed a highly significant first-order by linear higher-order sequence interaction $\left(\mathrm{F}=16.5, \mathrm{p}=.001\right.$, partial $\eta^{2}=$ .428), such that, for first-order repetitions, N2 increased over higher-order sequences from runs of repetitions to runs of alternations, and decreased over these sequences for first-order alternations. That is, a cost-benefit pattern was observed, where N2 amplitude increased with cost and decreased with benefit. Neither the first-order nor higher-order linear main effects reached significance (both $\mathrm{p}>$.123).

$$
<<\text { Insert Figure } 4 \text { about here }>>
$$

The response type contrast comparing Go vs. NoGo indicated NoGo N2 was not significantly increased overall $(F<1)$. Neither the interactions with first-order or higher-order sequences were significant (first-order: $\mathrm{F}=2.4, \mathrm{p}=.134$, partial $\eta^{2}=.099$; higher-order: $\mathrm{F}=3.8, \mathrm{p}=.063$, partial $\left.\eta^{2}=.148\right)$. The Go vs. NoGo $\mathrm{x}$ first-order $\mathrm{x}$ higher-order interaction also did not reach significance $\left(F<1\right.$, partial $\left.\eta^{2}=.027\right)$. Thus, Go and NoGo trials produced a similar increase in $\mathrm{N} 2$ over higher-order sequences for first-order repetitions, and a decrease over these sequences for first-order alternations. That is, there was no difference between Go and NoGo trials in the observed cost-benefit pattern for N2 amplitude.

For the Go vs. two-choice contrast, the main effect of response type was not significant $(\mathrm{F}<1$, partial $\left.\eta^{2}=.004\right)$. There were no significant interactions with first-order or higher-order sequences (first-order: $\mathrm{F}=1.7, \mathrm{p}=.208$, partial $\eta^{2}=.071$; higher-order; $\mathrm{F}=1.7, \mathrm{p}=.210$, partial $\left.\eta^{2}=.070\right)$. There was also no significant difference in the first-order $\mathrm{x}$ higher-order interaction between response types $\left(F<1\right.$, partial $\left.\eta^{2}=.003\right)$. That is, there was no difference in the costbenefit pattern observed for Go and two-choice trials for N2 amplitude.

N2 latency, averaged across response types, did not display the cost-benefit pattern: neither the first-order or higher-order main effects, nor the first-order by higher-order interaction approached significance. N2 latency was shorter for NoGo than Go trials $(F=15.9, \mathrm{p}=.001$, partial $\left.\eta^{2}=.419\right)$, and this effect was larger for first-order alternations than first-order repetitions $\left(\mathrm{F}=15.1, \mathrm{p}=.001\right.$, partial $\left.\eta^{2}=.406\right)$. The interaction between the Go vs. NoGo type and the linear contrast on the higher-order sequence factor was not significant $\left(F<1\right.$, partial $\left.\eta^{2}=.008\right)$. 
There was a significant three way interaction $\left(F=5.9, \mathrm{p}=.023\right.$, partial $\left.\eta^{2}=.213\right)$, such that for Go trials, there is a weak cost-benefit pattern, producing slightly increased N2 latency over higher order sequences for first order repetitions, and slightly decreased latency over those sequences for first-order alternations. On the other hand, NoGo N2 latency appears to show the opposite pattern, with a decrease over higher-order sequences for first-order repetitions, and an increase for first-order alternations. That is, Go N2 latency is slightly increased for unexpected stimuli, while NoGo N2 occurs earlier for unexpected stimuli. There were no significant main effects or interactions involving comparisons of Go and two-choice trial types (all p > .067). Thus, N2 peak latency showed some effects of trial sequence and type, and where effects conformed to a cost-benefit pattern, these were in opposite directions for Go and NoGo stimuli.

P3a amplitude showed the same overall cost-benefit pattern as N2 amplitude, as evidenced by a highly significant first-order $\mathrm{x}$ linear higher-order interaction $\left(\mathrm{F}=31.1, \mathrm{p}<.001\right.$, partial $\eta^{2}=$ .585). That is, P3a increased over higher-order sequences for first-order repetitions, and decreased over higher-order sequences for first-order alternations. First-order alternations produced a larger $\mathrm{P} 3 \mathrm{a}$ than first-order repetitions $\left(\mathrm{F}=8.1, \mathrm{p}=.010\right.$, partial $\left.\eta^{2}=.268\right)$, and P3a also decreased from runs of repetitions to runs of alternations $\left(F=10.16, p=.004\right.$, partial $\eta^{2}=$ .325). P3a was not globally significantly different for Go than NoGo trials $(F=1.4, p=.241$, partial $\left.\eta^{2}=.062\right)$, however, for first-order repetitions, P3a was larger for Go than NoGo trials, while the typical NoGo $>$ Go effect was observed for first-order alternations $(\mathrm{F}=11.2, \mathrm{p}=$ .003 , partial $\eta^{2}=.338$ ). This effect appeared mostly driven by the increased NoGo P3a to RRA and ARA sequences. P3a amplitude was significantly increased for two-choice compared to Go trials $\left(\mathrm{F}=5.7, \mathrm{p}=.026\right.$ partial $\left.\eta^{2}=.205\right)$. However, in contrast to $\mathrm{N} 2$ amplitude and RT, but like error rates, the cost-benefit pattern for P3a amplitude varied across response types. This was mainly due to the same insensitivity to higher-order sequence effects for all Go trials and for first-order repetition NoGo trials as was observed for errors. In particular, the cost-benefit pattern in P3a amplitude was much stronger for two-choice than Go trials $(\mathrm{F}=18.0, \mathrm{p}<.001$, partial $\left.\eta^{2}=.450\right)$ and somewhat stronger for NoGo than Go trials $\left(F=4.9, \mathrm{p}=.038\right.$, partial $\eta^{2}$ $=.182)$.

P3a latency did not display a cost-benefit pattern, with no significant interaction between firstorder and higher-order factors $\left(\mathrm{F}=2.2, \mathrm{p}=.157\right.$, partial $\left.\eta^{2}=.089\right)$. There was a first-order main effect, with an earlier P3a peak for first-order repetitions than alternations $(F=16.9, \mathrm{p}<.001$, partial $\left.\eta^{2}=.434\right)$. Go P3a latency was also earlier than two-choice latency $(F=7.0, p=.014$, 
partial $\eta^{2}=.243$ ), with no other main effects or interactions approaching significant (all $\mathrm{p}>$ $.166)$.

P3b amplitude showed a strong cost-benefit effect, signified by a highly significant first-order by higher-order interaction $\left(F=69.6, p<.001\right.$, partial $\left.\eta^{2}=.760\right)$. The first-order main effect was also significant, with increased $\mathrm{P} 3 \mathrm{~b}$ for first-order alternations compared to repetitions $(\mathrm{F}=36.8$, $\mathrm{p}<.001$, partial $\eta^{2}=.626$ ). P3b slightly but significantly decreased over higher-order sequences, regardless of the first-order effect $\left(F=5.7, p=.026\right.$, partial $\left.\eta^{2}=.207\right)$. For Go vs. NoGo comparisons, a number of effects were significant: P3b was significantly larger for Go than NoGo trials $\left(F=57.3, p<.001\right.$, partial $\left.\eta^{2}=.723\right)$, and this effect was larger for first-order repetitions than alternations $\left(F=5.1, p=.034\right.$, partial $\left.\eta^{2}=.189\right)$. Go P3b did not change substantially over higher-order sequences, while NoGo P3b showed a clear decrease $(\mathrm{F}=5.0, \mathrm{p}$ $=.036$, partial $\left.\eta^{2}=.185\right)$. However, the three-way interaction did not reach significance $(\mathrm{F}=2.0$, $\mathrm{p}=.168$, partial $\left.\eta^{2}=.085\right)$, indicating that the cost-benefit pattern was not significantly different between Go and NoGo trials for P3b.

For comparisons of Go and two-choice P3b, there was a significant type main effect, with larger P3b for Go than two-choice trials $\left(F=5.7, p=.026\right.$, partial $\left.\eta^{2}=.206\right)$. This effect was stronger for first-order alternations than repetitions $\left(F=5.4, p=.030\right.$, partial $\left.\eta^{2}=.196\right)$. Lastly, there was a significant three-way interaction, indicating a much stronger cost-benefit effect in the twochoice than Go trials $\left(F=20.0, \mathrm{p}<.001\right.$, partial $\left.\eta^{2}=.476\right)$.

P3b latency displayed a strong cost-benefit pattern, with shorter latencies for trials that continued a run, and longer latencies for trials that discontinued a run $(F=30.3, p<.001$, partial $\left.\eta^{2}=.580\right)$. P3 latency was also slightly but significantly shorter for first-order repetitions than first-order alternations $\left(F=6.4, p=.019\right.$, partial $\left.\eta^{2}=.227\right)$. P3b was also significantly earlier for Go than NoGo trials $\left(F=7.1, \mathrm{p}=.014\right.$, partial $\left.\eta^{2}=.243\right)$. No other effects on P3b latency were significant. Hence, a clear cost-benefit pattern was evident for all response types in P3b latency.

\section{Discussion}

There is currently a debate concerning whether increased N2 and P3 components observed for NoGo relative to Go trials reflects response inhibition (e.g., Kok et al., 2004), or the more general process of conflict (e.g., Smith et al., 2007). We examined expectancy effects in random sequences of trials to compare the inhibition and conflict accounts of the Go/NoGo task. We 
hypothesized that if an ERP component reflects inhibition it should show expectancy effects only for NoGo trials. In contrast, we hypothesised that if a component reflects conflict it should be increased for any unexpected stimulus, whether Go or NoGo, and so should display a costbenefit pattern for both trial types. As expectancy effects caused by random trial sequences have mainly been examined in two-choice tasks in the past, we also ran a two-choice condition. The two-choice condition provided benchmark behavioural results against which to compare corresponding results from the Go/NoGo task. We also examined N2 and P3 components in the two-choice task, both because sequence effects on N2 in two-choice tasks have received little attention in the past, and in order to compare them with corresponding components in the Go/NoGo task.

Our two-choice reaction time and error results replicated previous findings, showing the expected cost-benefit pattern. (e.g., Jentzsch \& Sommer, 2002; Laming, 1968; Remington, 1969, 1971). Although some anomalies in the RT effects for the two-choice task were apparent (a firstorder repetition effect, and asymmetries in the slopes for higher-order sequences), these were likely due to the unfamiliar colour to choice response mapping used for two-choice stimuli in this task (Jentzsch \& Sommer, 2002; Nieuwenhuis et al. 2003). Most importantly, however, the cost-benefit pattern was also clearly observed for Go response times, suggesting that similar subjective expectancies are generated in the two tasks.

However, the same cannot be said for choice and Go/NoGo error results. There were no sequence effects whatsoever on Go (omission) errors, nor on NoGo errors when the most recent trial was a repetition. The lack of any expectancy effects on errors for Go trials suggests that at least some of the corresponding RT effect was due to participants avoiding omission errors by making late responses to discontinued runs. For NoGo trials participants had trouble avoiding commission errors when a sequence dominated by repeated Go trials ended in an alternation (e.g., RRA). However, when a sequence dominated by alternating Go and NoGo trials ended in a pair of repeated NoGo trials (e.g., AAR) commission errors were not increased. In fact, like omission errors, the commission error rate was unaffected by higher-order sequences for first-order repetitions. Although these effects do not mirror the cost-benefit pattern observed for two-choice trials, the results are compatible with Nieuwenhuis et al.'s (2003) finding of a first-order effect for commission errors. In that study, participants made fewer errors to NoGo trials following another NoGo, compared to errors on NoGo trials which followed a Go. That is, commission errors were reduced for first-order repetitions relative to alternations. Taken 
together, these results suggest that inhibition of a response on NoGo trials is much easier if a response has been recently inhibited.

We found that the $\mathrm{N} 2 \mathrm{NoGo}>$ Go effect was not reliable across trial sequences. When observed, this effect is sometimes interpreted as evidence of inhibitory processing (e.g., Gemba \& Sasaki, 1989; Jodo \& Kayama, 1992; Kok, 1986; Nativ et al., 1992). However, later researchers posited that the increase in $\mathrm{N} 2$ instead reflects conflict between competing Go and NoGo decisions (e.g., Bruin, Wijers, \& van Staveren, 2001; Nieuwenhuis et al., 2003; Smith et al., 2007). Our analyses of higher-order sequence effects assist in distinguishing the conflict and inhibition interpretations of $\mathrm{N} 2$, since different predictions are made by the two interpretations. The response inhibition theory predicts that inhibition will be more difficult to unexpected than expected NoGo stimuli, producing a cost-benefit pattern for NoGo trials only. However, we found that the cost-benefit patterns displayed by the N2 component did not differ between Go and NoGo trials. This provides strong support for the conflict interpretation of N2, as N2 was increased for any unexpected stimulus, whether it required response activation or inhibition. Consequently, a reconsideration of the inhibition theory of N2 is warranted.

It is also noteworthy that we did not find a significant difference between the cost-benefit patterns for the N2 for Go and two-choice trials. The N2 has not been extensively examined in the two-choice task, although visual inspection of figures in Jentzsch and Sommer (2001) and Sommer et al. $(1990,1999)$ reveals that N2 appears larger for trials which discontinue rather than trials that continue a run, consistent with the results of the present study. If it is accepted that the Go/NoGo N2 cost-benefit pattern represents conflict, then this interpretation could be extended to the N2 results for the two-choice task. Indeed, Jentzsch and colleagues have recently argued that response conflict is the cause of the higher-order sequence effects in two-choice tasks using both short and long RSIs (Jentzsch and Leuthold, 2005; Dudschig and Jentzsch, 2008).

Broadly similar effects were found for the P3a and P3b components. First-order alternations elicited larger amplitudes than first-order repetitions, and the typical cost-benefit pattern was observed in the two-choice task, confirming the robust status of these findings (e.g., Gonsalvez, et al., 1995; Jentzsch \& Sommer, 2001; Johnson \& Donchin, 1980; Matt et al., 1992; Sommer et al., 1990, 1999; Squires et al., 1976). The typical increase for NoGo compared to Go P3a was not apparent in this study, although the NoGo P3a was increased for first-order alternation 
sequences, especially those where inhibition/conflict would be highest (RRA and ARA sequences). This effect was not apparent in P3b, with Go P3b always larger than NoGo P3b. For both P3a and P3b, effects of higher-order sequence for first-order alternations were strong for NoGo trials, and slightly weaker but nonetheless apparent for Go trials, suggesting that conflict rather than response inhibition drove the increased P3 to unexpected trials.

However, for first-order repetitions, neither Go nor NoGo trials were affected by the higherorder trial sequence. The latter result is contrary to both inhibition and conflict hypotheses, but this may be explained by comparison with the behavioural findings. Commission errors to NoGo trials also showed higher-order effects for first-order alternations, yet were unaffected by higher-order sequences for first-order repetitions. This was interpreted as a reduction in the difficulty of withholding a response when a response had been withheld on the previous trial. The indifference of the Go and NoGo P3a and P3b to higher-order sequences for first-order repetitions may thus confirm that conflict is reduced by transient priming of that response from the previous trial. It is unclear, however, why a different effect is observed for the two-choice $\mathrm{P} 3 \mathrm{~b}$, since we have argued that this also may elicit conflict.

On a more global level, it is interesting to note the similarity between N2 and RT results, and between $\mathrm{P} 3 \mathrm{a} / \mathrm{b}$ and error results. For both $\mathrm{P} 3$ components and errors, a) a cost-benefit pattern was displayed for two-choice responses, b) relative insensitivity to sequence effects was demonstrated for Go trials, and c) for NoGo trials, we observed insensitivity to higher-order sequences for first-order repetitions, but the expected change over higher-order sequences for first-order alternations. In contrast, for both Go and two-choice N2 and RT, a cost-benefit pattern was displayed, with almost no difference between trial types. Thus, the amplitude results for the two-choice task always showed the expected cost-benefit pattern, but the relationships of most interest occurred for Go and NoGo trials, and for these effects we have no reference in previous research. Therefore, the effects require replication and further experimentation to determine the cause of these unexpected relationships.

In the design of the current study, two stimuli were mapped to two responses for each task (green and red for the Go/NoGo task, and yellow/blue for the two-choice task). This limits our ability to localise the conflict as stimulus-related or response-related, since every repetition is a repeat of both stimulus and response (and likewise for alternations). However, recent research (Dudschig \& Jentzsch, 2008; Jentzsch \& Leuthold, 2005; Soetens, 1998) has mapped four stimuli 
to two (left/right) responses, allowing for repetition of both stimulus and response (so-called 'identical' trials), a change of stimulus with a repetition of response ('equivalent' trials), and a change of both stimulus and response ('different' trials). Slowing of responses on both equivalent and different relative to identical trials indicates stimulus-related conflict, while response slowing for different trials only represents response-related conflict. These studies have consistently shown that the locus of subjective expectancy is decision/response-related, both using reaction time and measures of the lateralised readiness potential (LRP). Thus, it may be valuable in future research to make use of this paradigm to disentangle the stimulus- and response-related aspects of conflict in the Go/NoGo task.

It should be noted that interpretations of the data other than in terms of conflict are possible. For example, the N2 results could also be explained as a mismatch-negativity (MMN)-like component (see also Folstein \& van Petten, 2008). The regularity-violation hypothesis of MMN (Winkler, 2007) holds that an MMN is elicited to any stimulus that violates a regular sequence of stimuli. That is, MMN is elicited not only in the oddball paradigm in which a globally rare deviant stimulus interrupts a train of globally frequent standard stimuli (in the terminology of random sequence methodologies, RRA), but also in an equiprobable, regularly alternating series interrupted with a stimulus repetition (AAR; Horváth, Czigler, Sussman, \& Winkler, 2001). However, to our knowledge, MMN has never been studied with the equiprobable random design used in the current study. In such designs, repetitions are just as likely as alternations, and all sequences of repetitions and alternations are equally likely, and thus the development of a memory trace for an expected stimulus or pattern may not be strong for any of the sequences. Thus, it is possible in principle that an MMN-like component may explain the N2 results reported here; however, much further work remains to be done to confirm this possibility.

An orienting interpretation of the results is also possible. The P3/late positive complex has recently been put forward as an ERP correlate of the orienting response (Rushby, Barry, \& Doherty, 2005; see also Barry \& Rushby, 2006, for an orienting-response perspective on the NoGo P3 in particular) and the relatively small P3 to RRR sequences could be evidence of habituation. Likewise, the larger P3 to RRA sequences could be interpreted as orienting to a change stimulus. However, orienting experiments do not make clear predictions about habituation to a regularly alternating series, and thus whether orienting would occur to an AAR sequence, since almost all studies use repetitive stimulation followed by a change stimulus. Thus, it is possible that the $\mathrm{P} 3$ results in our study (and many others using two-choice tasks) could be 
explained by orienting, if further work supports the notion of habituation to regularly alternating sequences, and response recovery to discontinued alternation sequences.

In summary, our work confirms that similar subjective expectancies are established in the Go/NoGo task as in the two-choice RT task. The N2 was increased for any unexpected stimulus, whether Go, NoGo or two-choice, supporting a conflict interpretation of the N2. The P3 displayed the usual cost-benefit pattern for the two-choice task, and was increased for both Go and NoGo stimuli that discontinued a repetitive run, also supporting a conflict account of P3. However, the P3 and error results suggest that conflict is reduced if the response has been recently performed. Thus, a conflict interpretation is supported for both N2 and P3 in the Go/NoGo task, yet they are affected in different ways by different stimulus sequences. This work confirms previous findings relating conflict to these components, but presents a new methodological approach. The study of sequence effects allows the examination of expectancy, free from the problems associated with globally infrequent NoGo stimuli, or the confounding overlap of ERPs in tasks with cue-target structures. 


\section{References}

Band, G.P.H., Ridderinkhof, K.R., \& van der Molen, M.W. (2003). Speed-accuracy modulation in case of conflict: the roles of activation and inhibition. Psychological Research, 67, 266-279.

Barry, R.J., \& Rushby, J.A. (2006). An orienting reflex perspective on anteriorisation of the P3 of the event-related potential. Experimental Brain Research, 173, 539-545.

Bekker, E.M., Kenemans, J.L., Koeksma, M.R., Talsma, D., \& Verbaten, M.N. (2005). The pure electrophysiology of stopping. International Journal of Psychophysiology, 55, 191-198.

Bekker, E.M., Kenemans, J.L., \& Verbaten, M.N. (2004). Electrophysiological correlates of attention, inhibition, sensitivity and bias in a continuous performance task. Clinical Neurophysiology, 115, 2001-2013.

Bertelson, P. (1961). Sequential redundancy and speed in a serial two-choice responding task. Quarterly Journal of Experimental Psychology, 13, 90-102.

Bokura, K., Yamaguchi, S., \& Kobayashi, S. (2001). Electrophysiological correlates for response inhibition in a Go/NoGo task. Clinical Neurophysiology 112: 2224-2232.

Braver, T.S., Barch, D.M., Gray, J.R., Molfese, D.L., \& Snyder, A. (2001). Anterior cingulate cortex and response conflict: Effects of frequency, inhibition and errors. Cerebral Cortex, $11,825-836$.

Bruin, K.J., \& Wijers, A.A. (2002). Inhibition, response mode, and stimulus probability: a comparative event-related potential study. Clinical Neurophysiology, 113, 1172-1182.

Bruin, K.J., Wijers, A.A., \& van Staveren, A.S.J. (2001). Response priming in a go/nogo task: do we have to explain the go/nogo N2 effect in terms of response activation instead of inhibition? Clinical Neurophysiology, 112, 1660-1671.

Dimoska, A., Johnstone, S.J., \& Barry, R.J. (2006). The auditory-evoked N2 and P3 components in the stop-signal task: Indices of inhibition, response-conflict or error-detection? Brain and Cognition, 62, 98-112.

Donchin, E., \& Coles, M.G.H. (1988). Is the P300 component a manifestation of context updating? Behavioural and Brain Sciences, 11, 357-374.

Donkers, F.C.L., \& Van Boxtel, G.J.M. (2004). The N2 in go/no-go tasks reflects conflict monitoring not response inhibition. Brain and Cognition, 56, 165-176.

Dudschig, C., \& Jentzsch, I. (2008). Locus of response slowing resulting from alternation-based processing interference. Psychophysiology, 45, 751-758. 
Durston, S., Thomas, K.M., Worden, M.S., Yang, Y., \& Casey, B.J. (2002). The effect of preceding context on inhibition: An event-related fMRI study. NeuroImage, 16, 449-453.

Durston, S., Thomas, K.M., Yang, Y., Ulug, A.M., Zimmerman, R.D., \& Casey, B.J. (2002). A neural basis for the development of inhibitory control. Developmental Science, 5, F9-F16.

Folstein, J.R., \& Van Petten, C. (2008). Influence of cognitive control and mismatch on the N2 component of the ERP: A review. Psychophysiology, 45, 152-170.

Garavan, H., Hester, R., Murphy, K., Fassbender, C., \& Kelly, C. (2006). Individual differences in the functional neuroanatomy of inhibitory control. Brain Research, 1105, 130-142.

Garavan, H., Ross, T.J., Murphy, K., Roche, R.A.P., \& Stein, E.A. (2002). Dissociable executive functions in the dynamic control of behavior: inhibition, error detection, and correction. NeuroImage, 17, 1820-1829.

Gehring, W.J., Gratton, G., Coles, M.G.H., \& Donchin, E. (1992). Probability effects on stimulus evaluation and response processes. Journal of Experimental Psychology: Human Perception and Performance, 18, 198-216.

Gemba, H., \& Sasaki, K. (1989). Potential related to no-go reaction of go/no-go hand movement task with color discrimination in human. Neuroscience Letters, 101, 263-268.

Golob, E.J., \& Starr, A. (2000). Effects of stimulus sequence on event-related potentials and reaction time during target detection in Alzheimer's disease. Clinical Neurophysiology, 111, 1438-1449.

Gomez, P., Ratcliff, R., \& Perea, M. (2007). A model of the Go/No-Go task. Journal of Experimental Psychology: General, 136, 389-413.

Gonsalvez, C.J., Gordon, E., Anderson, J., Pettigrew, G., Barry, R.J., Rennie, C., \& Meares, R. (1995). Numbers of preceding nontargets differentially affect responses to targets in normal volunteers and patients with schizophrenia: A study of event-related potentials. Psychiatry Research, 58, 69-75.

Gonsalvez, C.J., \& Polich, J. (2002). P300 amplitude is determined by target-to-target interval. Psychophysiology, 39, 388-396.

Heil, M., Osman, A., Wiegelmann, J., Rolke, B., \& Hennighausen, E. (2000). N200 in the Eriksen-Task: Inhibitory Executive Processes? Journal of Psychophysiology, 14, 218-225.

Horváth, J., Czigler, I., Sussman, E., \& Winkler, I. (2001). Simultaneously active pre-attentive representations of local and global rules for sound sequences in the human brain. Cognitive Brain Research, 12, 131-144.

Jarvik, M.E. (1951). Probability learning and a negative recency effect in the serial anticipation of alternative symbols. Journal of Experimental Psychology, 41, 291-297. 
Jentzsch, I., \& Leuthold, H. (2005). Response conflict determines sequential effects in serial response time tasks with short response-stimulus intervals. Journal of Experimental Psychology: Human Perception and Performance, 31, 731-748.

Jentzsch, I., \& Sommer, W. (2001). Sequence-sensitive subcomponents of P300: Topographical analyses and dipole source localisation. Psychophysiology, 38, 607-621.

Jentzsch, I., \& Sommer, W. (2002). Functional localisation and mechanisms of sequential effects in serial reaction time tasks. Perception and Psychophysics, 64, 1169-1188.

Jodo, E., \& Kayama, Y. (1992). Relation of a negative ERP component to response inhibition in a Go/No-go task. Electroencephalography and Clinical Neurophysiology, 82, 477-482.

Johnson, R., \& Donchin, E. (1980). P300 and stimulus categorization: two plus one is not so different from one plus one. Psychophysiology, 17, 167-178.

Kirby, N.H. (1976). Sequential effects in two-choice reaction time: Automatic facilitation or subjective expectancy? Journal of Experimental Psychology: Human Perception and Performance, 2, 567-577.

Kok, A. (1986). Effects of degradation of visual stimuli on components of the event-related potential (ERP) in go/nogo reaction tasks. Biological Psychology, 23, 21-38.

Kok, A., Ramautar, J.R., De Ruiter, M.B., Band, G.P.H., \& Ridderinkhof, K.R. (2004). ERP components associated with successful and unsuccessful stopping in a stop-signal task. Psychophysiology, 41, 9-20.

Kopp, B., Mattler, U., Goertz, R., \& Rist, F. (1996). N2, P3 and the lateralised readiness potential in a nogo task involving selective response priming. Electroencephalography and Clinical Neurophysiology, 99, 19-27.

Laming, D.R.J. (1968). Information theory of choice-reaction times. London: Academic Press.

Loftus, G.R., \& Masson, M.E.J. (1994). Using confidence intervals in within-subject designs. Psychonomic Bulletin and Review, 1, 476-490.

Mäntysalo, S. (1987). N2 and P3 of the ERP to Go and Nogo stimuli: a stimulus-response association and dissociation. Current Trends in Event-Related Potential Research. New York, Elsevier. EEG Supplement 40: 227-234.

Matt, J., Leuthold, H., \& Sommer, W. (1992). Differential effects of voluntary expectancies on reaction times and event-related potentials: Evidence for automatic and controlled expectancies. Journal of Experimental Psychology: Learning, Memory and Cognition, 18, 810-822.

Mostofsky, S.H., Schafer, J.G.B., Abrams, M.T., Goldberg, M.C., Flower, A.A., Boyce, A., Courtney, S.M., Calhoun, V.D., Kraut, M.A., Denckla, M.B., \& Pekar, J.J. (2003). fMRI 
evidence that the neural basis of response inhibition is task-dependent. Cognitive Brain Research, 17, 419-430.

Nativ, A., Lazarus, J.-a.C., Nativ, J., \& Joseph, J. (1992). Potentials associated with the initiation and inhibition of visually triggered finger movement in humans: The "NoGo potential" in the Go/NoGo paradigm. International Journal of Neuroscience, 66, 107-118.

Nieuwenhuis, S., Stins, J.F., Posthuma, D., Polderman, T.J.C., Boomsma, D.I., \& de Geus, E.J. (2006). Accounting for sequential trials effects in the flanker task: conflict adaptation or associative priming? Memory and Cognition, 34, 1260-1272.

Nieuwenhuis, S., Yeung, N., van den Wildenberg, W., \& Ridderinkhof, K.R. (2003). Electrophysiological correlates of anterior cingulate function in a go/no-go task: Effects of response conflict and trial type frequency. Cognitive, Affective and Behavioral Neuroscience, 3, 17-26.

O’Brien, R.G., \& Kaiser, M.K. (1985) MANOVA method for analyzing repeated measures designs: An extensive primer. Psychological Bulletin, 97, 316-333.

Ofek, E., \& Pratt, H. (2004). Ear advantage and attention: an ERP study of auditory cued attention. Hearing Research, 189, 107-118.

Pfefferbaum, A. \& Ford, J.M. (1988). ERPs to stimuli requiring response production and inhibition: effects of age, probability and visual noise. Electroencephalography and Clinical Neurophysiology, 71, 55-63.

Remington, R.J. (1969). Analysis of sequential effects in choice reaction times. Journal of Experimental Psychology, 82, 250-257.

Remington, R.J. (1971). Analysis of sequential effects for a four-choice reaction time experiment. The Journal of Psychology, 77, 17-27.

Rubia, K., Russell, T., Overmeyer, S., Brammer, M.J., Bullmore, E.T., Sharma, T., Simmons, A., Williams, S.C.R., Giampietro, V., Andrew, C., \& Taylor, E. (2001). Mapping motor inhibition: Conjunctive brain activations across different versions of Go/No-Go and Stop tasks. NeuroImage, 13, 250-261.

Rushby, J.A., Barry, R.J., \& Doherty, R.J. (2005). Separation of the components of the late positive complex in an ERP dishabituation paradigm. Clinical Neurophysiology, 116, 23632380.

Sams, M., Alho, K., \& Näätänen, R. (1983). Sequential effects on the ERP in discriminating two stimuli. Biological Psychology, 17, 41-58.

Semlitsch, H.V., Anderer, P., Schuster, P., \& Presslich, O. (1986). A solution for reliable and valid reduction of ocular artifact, applied to the P300 ERP. Psychophysiology, 23, 695-703. 
Smith, J.L., Johnstone, S.J., \& Barry, R.J. (2006). Effects of pre-stimulus processing on subsequent events in a warned Go/NoGo paradigm: Response preparation, execution and inhibition. International Journal of Psychophysiology, 61, 121-133.

Smith, J.L., Johnstone, S.J., \& Barry, R.J. (2007). Response priming in the Go/NoGo task: The N2 reflects neither inhibition nor conflict. Clinical Neurophysiology, 118, 343-355.

Smith, J.L., Johnstone, S.J., \& Barry, R.J. (2008). Movement-related potentials in the Go/NoGo task: The P3 reflects both cognitive and motor inhibition. Clinical Neurophysiology, 119, 704-714.

Snodgrass, J.G., \& Corwin, J. (1988). Pragmatics of measuring recognition memory: Applications to dementia and amnesia. Journal of Experimental Psychology: General, 117, 34-50.

Soetens, E. (1998). Localising sequential effects in serial choice reaction time with the information reduction procedure. Journal of Experimental Psychology: Human Perception and Performance, 24, 547-568.

Sommer, W., Leuthold, H., \& Soetens, E. (1999). Covert signs of expectancy in serial reaction time tasks revealed by event-related potentials. Perception and Psychophysics, 61, 342-353.

Sommer, W., Matt, J., \& Leuthold, H. (1990). Consciousness of attention and expectancy as reflected in event-related potentials and reaction times. Journal of Experimental Psychology: Learning, Memory and Cognition, 16, 902-915.

Squires, K.C., Petuchowski, S., Wickens, C., \& Donchin, E. (1977). The effects of stimulus sequence on event related potentials: A comparison of visual and auditory sequences. Perception and Psychophysics, 22, 31-40.

Squires, K.C., Wickens, C., Squires, N.K., \& Donchin, E. (1976). The effect of stimulus sequence on the waveform of the cortical event-related potential. Science, 193, 1142-1145.

Starr, A., Sandroni, P., \& Michalewski, H.J. (1995). Readiness to respond in a target detection task: pre- and post-stimulus event-related potentials in normal subjects. Electroencephalography and Clinical Neurophysiology, 96, 76-92.

Tabachnick, B.G., \& Fidell, L.S. (1996). Using multivariate statistics. New York: HarperCollins.

Vallesi, A., McIntosh, A.R., Alexander, M.P., \& Stuss, D.T. (2009). FMRI evidence of a functional network setting the criteria for withholding a response. NeuroImage, 45, 537548.

van Boxtel, G.J.M., van der Molen, M.W., Jennings, J.R., \& Brunia, CH.M. (2001). A psychophysiological analysis of inhibitory motor control in the stop-signal paradigm. Biological Psychology, 58, 229-262. 
van Veen, V., \& Carter, C.S. (2002). The timing of action-monitoring processes in the anterior cingulate cortex. Journal of Cognitive Neuroscience, 14, 593-602.

Verbruggen, F., Logan, G.D., Liefooghe, B., \& Vandierendonck, A. (2008). Short-term aftereffects of response inhibition: Repetition priming or between-trial control adjustments? Journal of Experimental Psychology: Human Perception and Performance, 34, 413426.

Wang, Y., Tian, S., Wang, H., Cui, L., \& Zhang, Y. (2002). Event-related potentials in a no-go task involving response-tendency conflict. Clinical Electroencephalography 33, 82-85.

Watanabe, J., Sugiura, M., Sato, K., Sato, Y., Maeda, Y., Matsue, Y., Fukuda, H., \& Kawashima, R. (2002). The human prefrontal and parietal association cortices are involved in No-Go performances: an event-related fMRI study. NeuroImage, 17, 1207-1216.

Winkler, I. (2007). Interpreting the mismatch negativity. Journal of Psychophysiology, 21, 147-163. 


\section{Author notes}

Acknowledgements: We wish to thank Mr Gavin Cooper for writing the stimulus presentation programs.

Address for reprints:

Janette Smith

School of Psychology

University of Newcastle

Ourimbah NSW 2258

Australia

janette.smith@newcastle.edu.au 


\section{Figure captions}

Figure 1. Sequence effects on reaction time (top) and error rates (bottom) for the Go/NoGo and two-choice tasks. Error bars represent the within-subject standard error of the mean (SEM; Loftus \& Masson, 1994). For trial sequences, the most recent transition is listed last.

Figure 2. Grand mean ERPs to two-choice, Go and NoGo stimuli at three midline sites. Amplitude in microvolts and time in ms marked at top left. Colours denote different higherorder sequences, from red denoting a run of repetitions to purple denoting a run of alternations. Within the set of waveforms for each trial type, first-order (FO) repetitions are shown on the left, and FO alternations shown on the right. Thus, the cost-benefit effect is shown with increasing P3 from red to purple for FO repetitions, and decreasing P3 from red to purple for FO alternations.

Figure 3. Grand mean ERPs to two-choice, Go and NoGo trials for three midline sites, for firstorder repetitions which continue or discontinue a run (RRR and AAR, respectively), and firstorder alternations which continue or discontinue a run (AAA and RRA, respectively). Amplitude in microvolts and time in ms marked at $\mathrm{Fz}$, top left.

Figure 4. Sequence effects on N2 (left) and P3 (right) peak amplitude at three midline sites (top three) and peak latency (bottom), for Go, NoGo and two-choice trials. Error bars represent the standard error of the mean (SEM). For trial sequences, the most recent transition is listed last. 
Figure 1.

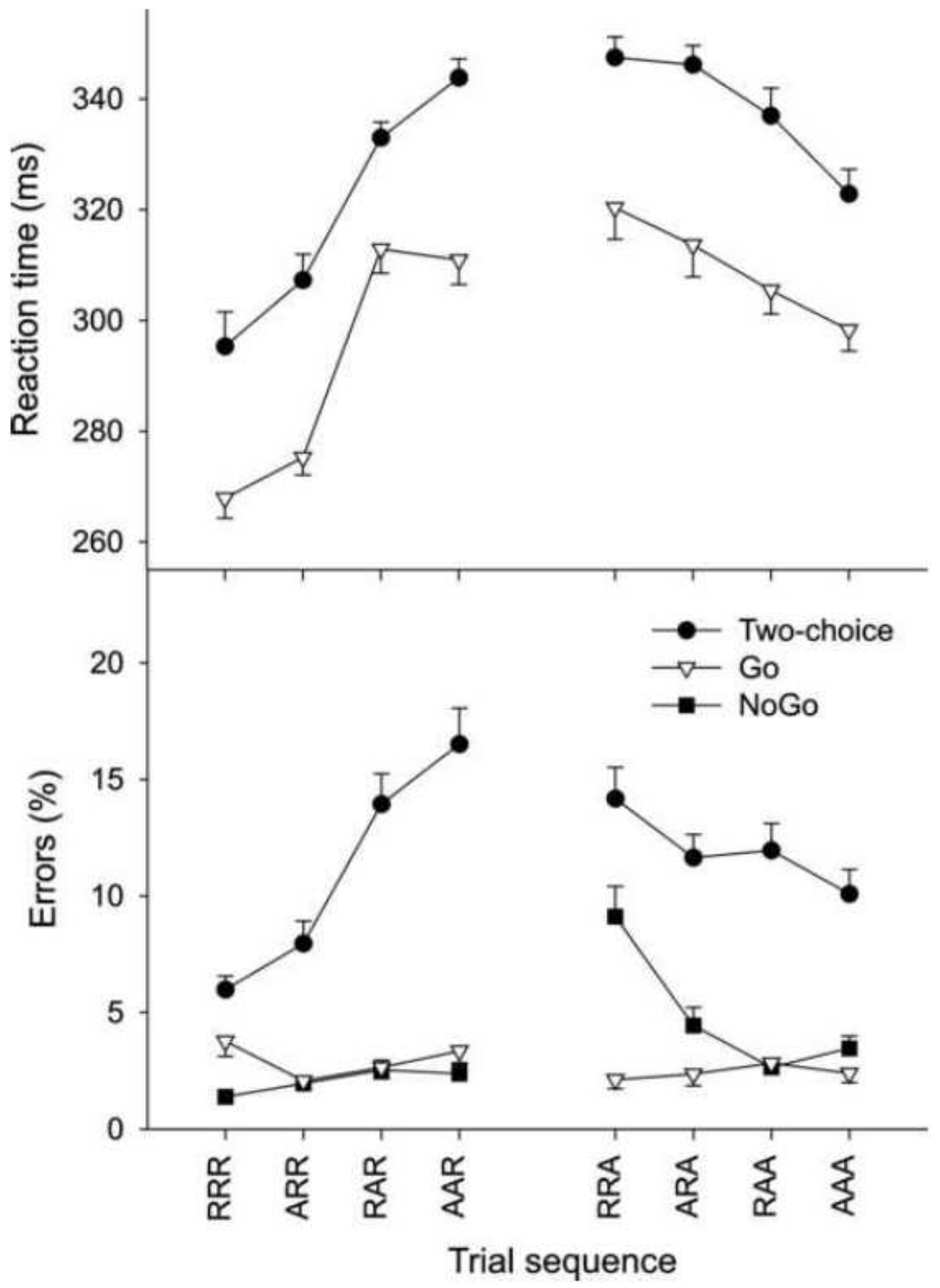


Figure 2.

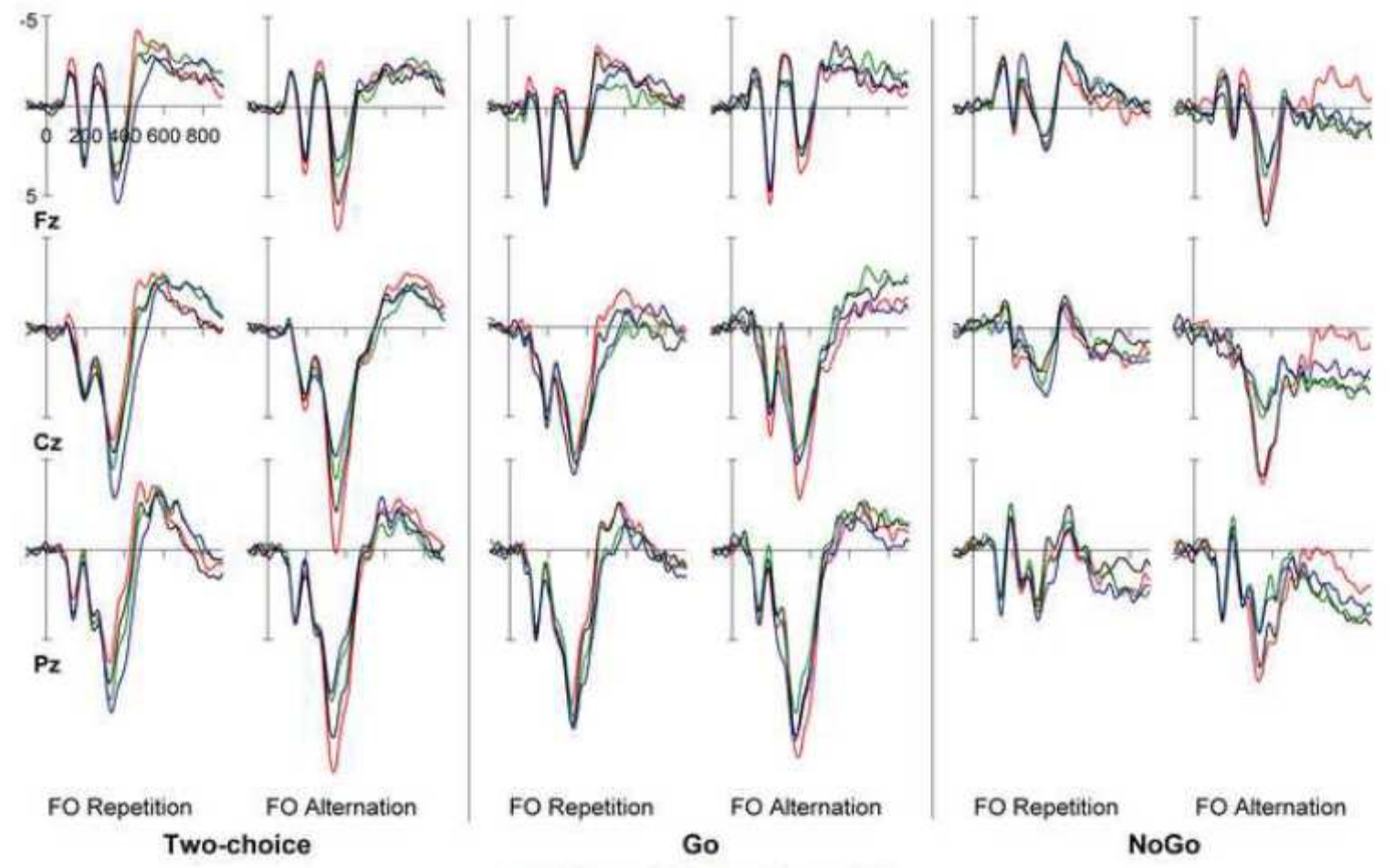

$-R R x-A R x-R A x-A A x$ 
Figure 3.

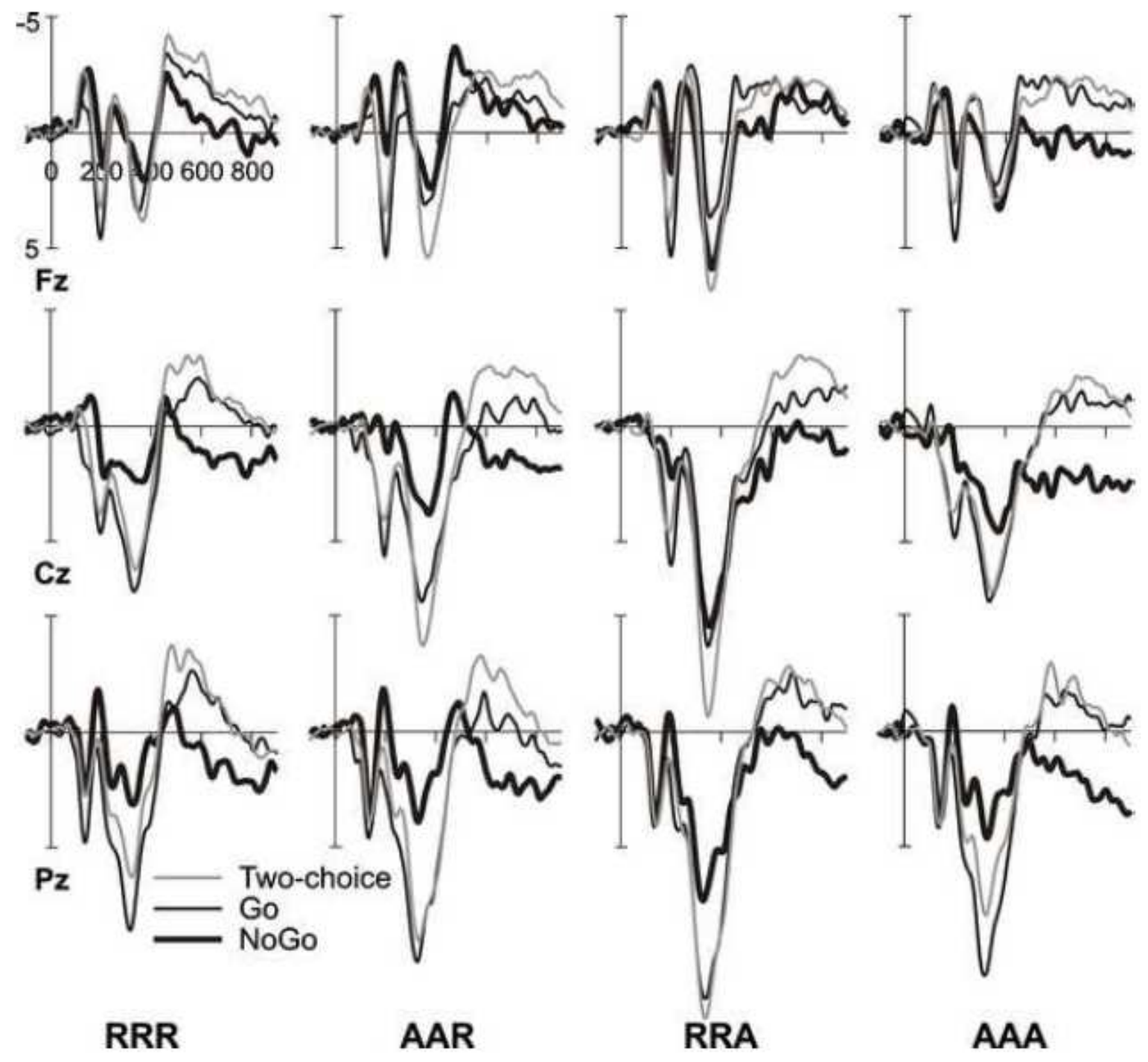


Figure 4.
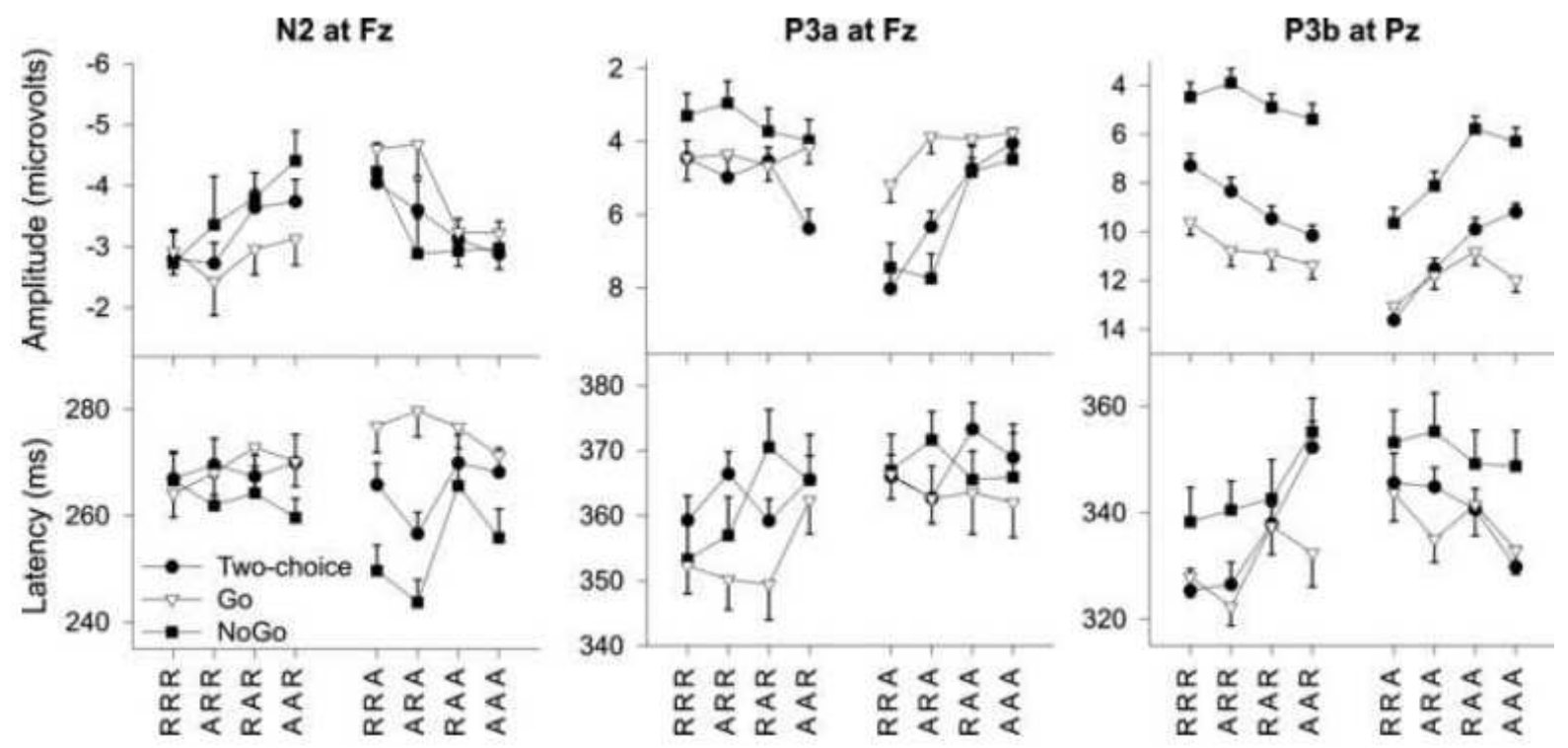